\title{
Effects of phonological phrasing on syntactic structure*
}

\author{
NANCY C. KULA
}

\begin{abstract}
Bantu languages are renowned as tone languages that utilize this suprasegmental feature not only on the lexical level to distinguish lexical items, but also on the grammatical level to distinguish clause types. This article investigates one such use of grammatical tone in relative clauses in Bemba where a low tone can be used in place of a segmental relative marker. This low tone relative morpheme functions in conjunction with phrase boundary tone indicated on the head noun and which entails either restrictive or non-restrictive interpretations of relatives. Considering a mapping of XPs to major phonological phrases in the syntax-prosody interface, the resultant phonological phrasing in relatives influences the choice of syntactic structure. In the case at hand, a head-raising analysis provides an optimal mapping between syntax and prosody for restrictives. Further, a more direct influence of phonology on syntax can be seen in a perception-based model like Dynamic Syntax where the on-line building of syntactic trees can gain import from phonological information.
\end{abstract}

\section{Introduction}

This article investigates how boundary tone in the phonological phrasing of Bemba interacts with relative clauses that are segmentally (relative marker/ pronoun) or tonally marked. ${ }^{1}$ Three factors in this interaction will be salient.

\footnotetext{
* I would like to express my thanks to Lisa Cheng with whom I have discussed the syntax of relative clauses, Lutz Marten and Ruth Kempson for enhancing my understanding of Dynamic Syntax, the editors and two anonymous reviewers who have greatly improved the clarity of the argument presented in this paper. The usual disclaimers apply. This research is supported by NWO VENI grant 27570006

1. Bemba (M42) is spoken in the Northern and Copperbelt provinces of Zambia. Data are from
}

The Linguistic Review 24 (2007), 201-231

DOI 10.1515/TLR.2007.008
0167-6318/07/024-0201

(c)Walter de Gruyter

1st proofs - preliminary page and line breaks! | Mouton de Gruyter 
Firstly, the presence of conjoint high tone on the final syllable of the head noun implies a restrictive relative, while conversely the absence of conjoint high tone implies a non-restrictive relative. Secondly, a relative clause marked by tone always induces a restrictive interpretation of the relative clause. Finally, headless relatives cannot be marked by tone. These factors will, on the one hand, be analysed as following from alignment constraints on phonological phrases, which in turn act as the basis for choosing one syntactic structure over another. On the other hand, they can be seen as providing salient information for syntactic structure building in a perception-based grammar. The two analyses thus contrast an interface and a feeding approach to the syntax-phonology mapping.

The article proceeds as follows. Section 2 presents an overview of phonological phrasing in Bemba. Section 3 outlines the strategies for relative clause formation and how these interact with restrictive and non-restrictive interpretations. Section 4 provides an interface account of the facts couched in Optimality Theory. Section 5 investigates a feeding relation between phonology and syntax in Dynamic Syntax, and Section 6 offers some concluding remarks.

\section{Phonological phrasing in Bemba}

Phonological phrasing in Bemba is generally marked by low tone and/or pause at the end of a major phrase (MaP). ${ }^{2}$ A high tone, referred to henceforth as conjoint high tone, signals that the constituent bearing the high tone is not phrase final. ${ }^{3}$ In verb phrases this differentiates broad focus from narrow focus. In addition to boundary tone, the pause that usually accompanies MaP boundaries is also segmentally manifested in the absence of vowel fusion whenever the conditions for this are met. Consider the phonological phrasings induced under different scopes of focus in (1). ${ }^{4}$ (MaPs are indicated by parenthesis).

Fred Kula and Honoria Mutale. Principal written sources used are van Sambeek (1955), Sharman (1956), Sharman and Meeussen (1955), Givón (1972), and Oger (1979).

2. I follow in broad terms the basic assumptions of phrasal phonology as presented in, for example, Selkirk (1984); Nespor and Vogel (1986). The focus here is mainly on phonological phrases referred to as major phrases (MaPs).

3. Conjoint and disjoint are terms used in the Bantu literature, usually with reference to verbs, but will also be used here with reference to nouns. Conjoint forms indicate tonally (or segmentally) that they are not final in their clause, while disjoint forms conversely indicate that they are clause final. Since this distinction is marked on the conjoint forms in Bemba, I will make reference to conjoint tone rather than disjoint tone. Conjoint tone will therefore indicate that no MaP boundary follows the marked constituent.

4. The following abbreviations are used in the glosses in the remainder of the article, (numbers refer to agreement classes): 


\author{
a. (n-ali-móna $)_{\mathrm{MaP}}$ (umwáána $)_{\mathrm{MaP}} \quad$ (verb focus) \\ 1SM-TNS-see 1child \\ 'I saw the child.' \\ b. (n-ali-mónóómwáána) $)_{\mathrm{MaP}} \quad$ (object focus/VP focus) \\ 'I saw the child.' $1 \mathrm{SM}-\mathrm{TNS}-\mathrm{see}$.1child 18tree
'I saw a child in a tree.' \\ c. (n-alí-mónóómwáána $)_{\mathrm{MaP}} \quad(\text { mucímuti) })_{\mathrm{MaP}} \quad$ (object focus \\ d. (n-ali-mónóómwááná mucímuti) $)_{\mathrm{MaP}} \quad$ (VP focus) \\ $1 \mathrm{SM}-\mathrm{TNS}-\mathrm{see}$.1child 18tree \\ 'I saw a child in a tree.'
}

Considering that focused constituents are final in MaPs, (1a) with a focused verb bears no final conjoint high tone and is, as a result, phrased separately from the object. (1b) with object or VP focus has final conjoint high tone on the verb, indicating that it is not final in the MaP. This is also indicated by vowel fusion (underlined) between the verb and the object that is by contrast absent in (1a). Similarly, object focus in (1c), which also includes a locative object (mисі́muti 'in the tree'), is indicated by the absence of final conjoint high tone on the focused object, in contrast to (1d) where its presence implies no phonological phrase boundary and hence broad (VP) focus. While other factors may be relevant for establishing minor and intonational phrases the current diagnostics will suffice for the present exposition that focuses on MaPs.

For phrasing in relative clauses it will be shown that the presence of the final conjoint high tone on the head noun implies that a following relative clause is within the same $\mathrm{MaP}$ as the head noun. Its absence, on the other hand, indicates that the head noun is final in its MaP. This will correlate to the restrictive versus non-restrictive interpretations of relatives, respectively.

\title{
3. Strategies for relative clause formation
}

Research on relative clauses in Bantu can be found in Meeussen (1971); Givón (1972); Nsuka (1982); Walusimbi (1996), and more recently Henderson (2006). The focus of these studies has either been typological or syntactic, in which

$\begin{array}{llll}\text { DEM } & \text { demonstrative } & \text { PERF } & \text { perfective } \\ \text { REL } & \text { relative marker } & \text { NEG } & \text { negative } \\ \text { TNS } & \text { tense } & \text { SG } & \text { singular } \\ \text { SM } & \text { subject marker } & \text { PPF } & \text { pre-prefix } \\ \text { OM } & \text { object marker } & \text { PFX } & \text { noun class prefix } \\ \text { STAT } & \text { stative } & \text { LOC } & \text { locative } \\ \text { COP } & \text { copular } & & \end{array}$


case, the latter is hardly ever informed by the tonal aspect of relatives (but see, Kamwangamalu 1988). Tonally marked relatives are widespread in Bantu and can be found in, Luganda, Kinyarwanda, Nsenga, Chichewa, Umbundu, Luba, to name but a few.

In Bemba, relative clauses can be marked with either a segmental or a tonal relative marker. Subject and object relatives differ in some respects. Both can be marked with a segmental relative marker, albeit of different shapes, but only the subject relative can be unambiguously tonally marked. As in many languages, the segmental relative marker can be optionally omitted in object relatives.

\subsection{Relative marking in subject relatives}

Subject relatives can be marked by either a bound segmental morpheme or by a tonal strategy that places a low tone on the subject agreement marker. ${ }^{5}$ Let us start with segmental marking. As shown in (2), segmentally marked relatives can follow both a head noun that bears the conjoint high tone and one that does not. In the former case (2b), a restrictive interpretation of the relative clause, restricting the reference of the head noun, holds; while in the latter (2c), a nonrestrictive interpretation must hold. (2a) is the simple sentence from which the relatives are derived.

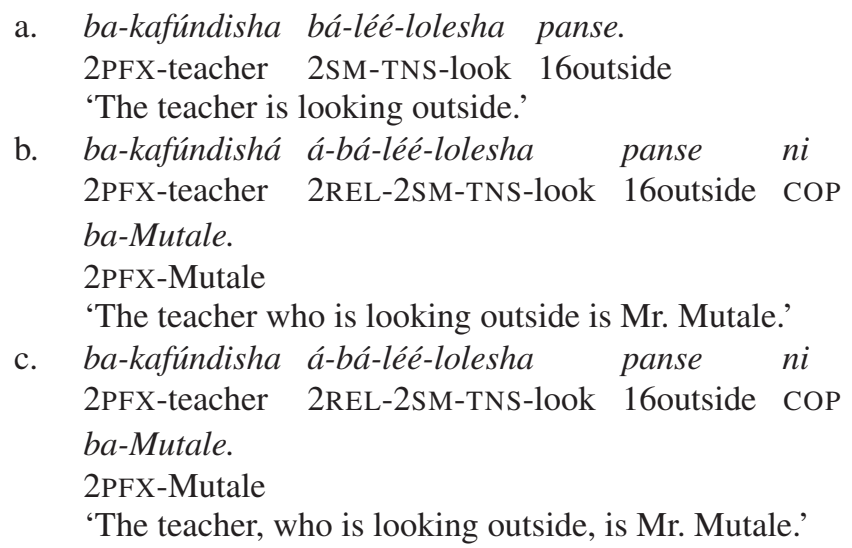

As in the case of VP phrasing illustrated in Section 2, the conjoint high tone on the head noun 'teacher' in (2b) indicates that it is not final in its MaP and hence phonologically phrases with the following relative clause. In (2c), on the other

5. The bound morpheme that acts as relative marker is referred to as the pre-prefix or augment in nominal agreement in Bantu. 
hand, the absence of the final conjoint high tone indicates that the head noun is final in its MaP. The two phrasings respectively contrast restrictive and nonrestrictive interpretations of the relative clause. ${ }^{6}$ Within segmentally marked subject relatives, it is not possible to omit the relative marker while retaining a relative interpretation. Thus, omitting the relative marker in (2c), for example, would result in the simple sentence (2a).

Coming now to tonally marked relatives, indicated by a low tone on the subject agreement marker, we see that while in (3a) a restrictive interpretation indicated by a conjoint high tone can hold, a non-restrictive cannot (3b). ${ }^{7} \mathrm{We}$ take (2a) as the base sentence.

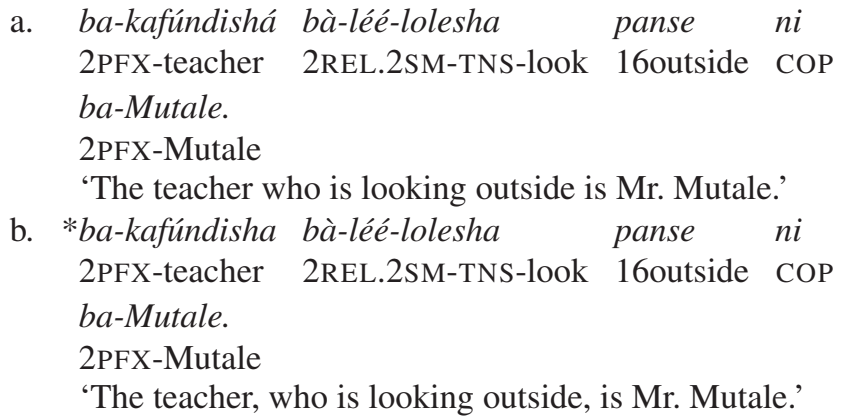

Recall that in the simple sentence (2a) the subject agreement marker (bá-) on the verb has a high tone. This means that the relative in (3a), cannot be derived merely by omitting the segmental relative marker in $(2 b)$, for example. Relativization must involve the active insertion of low tone, overriding the high, on the subject agreement marker. However, as (3) shows, the low tone strategy of relativization must co-occur with the conjoint high tone that marks restrictives. In order to show that this high tone is not responsible for relativization, consider the sentence in (4) where the head noun has conjoint high tone and the subject marker retains its high tone.

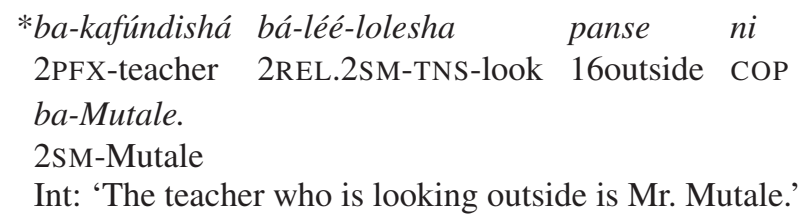

6. This marks a departure from Cheng and Kula (2006) where the focus was on the tonal strategy as inducing a restrictive interpretation of relatives.

7. I follow Cheng and Kula (2006) in treating this low tone as a tonal morpheme that is functionally equivalent to its segmental counterpart. 
The ungrammaticality of (4) as a relative confirms that the low tone on the subject agreement marker is what marks relativization in (3a). Thus, we must explain why the tonal strategy cannot be used to mark non-restrictives, or in terms of phrasing, why a tonally marked relative must be within the same MaP as the head noun. I return to these issues in Sections 4 and 5.

A final observation to make on subject relative marking in Bemba is that the segmental relative marker and the low tone morpheme cannot co-occur but are rather in complementary distribution.

\subsection{Relative marking in object relatives}

In object relatives, mainly a segmental marker is used to mark relatives while the tonal strategy has diminished use, limited to cases of disambiguation. Unlike subject relatives, the segmental marker is a free morpheme based on a demonstrative. ${ }^{8}$ As shown in (5), demonstratives and relative markers can cooccur, hence the independent status of the relative markers can be established.

$$
\begin{array}{llll}
\text { abántú abó ábo } & n \text {-a-mwééne } & \text { maíló... } \\
\text { 2people 2DEM 2REL } & \text { 1SM-TNS-See.PERF } & \text { yesterday } \\
\text { 'those people who/that I saw yesterday ...' } &
\end{array}
$$

As seen in (5), segmental relative markers in object relatives are independent prosodic words (on a par with demonstratives) that agree with the head noun in class. (6) illustrates that the segmental relative marker in object relatives, as in subject relatives, can occur with both a head noun bearing conjoint high tone (6b) and one that does not (6c). This means it can be used to mark both restrictive and non-restrictive relatives. (6a) is the simple sentence from which the object relatives are derived.

a. Chisanga á-mwééne abántu maílo. Chisanga 1SM-see.PERF 2person yesterday 'Chisanga saw people yesterday.'

b. abántu ábo Chisanga á-mwééne maílo 2person 2REL Chisanga 1SM-see.PERF yesterday $n a-b a ́-y a$.

TNS-2SM-go

'The people, who Chisanga saw yesterday, have gone.'

8. There are four series of demonstratives in Bemba; speaker-proximate, proximate, hearerproximate and distal. Based on the last two demonstratives, two relative markers are derived by a change in tone. The demonstratives are Low-High, while the relative markers are HighLow. 


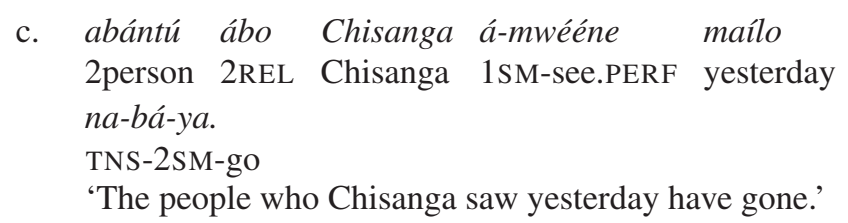

In contrast to subject relatives though, the segmental marker is always optional in object relatives. When the relative marker is absent (7a), a restrictive interpretation holds, and it is not possible for the conjoint high tone to be absent (7b). (6a) is the base sentence.
a. abántú Chisanga á-mwééne maíló na-bá-ya. 2person Chisanga 1SM-see.PERF yesterday TNS-2SM-go 'The people who Chisanga saw yesterday have gone.'
b. abántu Chisanga á-mwééne maíló na-bá-ya.
2person Chisanga 1SM-see.PERF yesterday TNS-2SM-go 'The people, who Chisanga saw yesterday, have gone.'

In (7a), where the relative marker ábo is omitted, the clause headed by Chisanga is still a relative clause modifying the head noun abántú 'people'.

With respect to the tonal marking strategy, object relatives exhibit some restrictions. As opposed to subject relatives, it is not possible to just omit the segmental relative marker and use low tone on the subject agreement marker instead (8a). A property of object relatives that is widespread across Bantu is the possibility to invert the subject within the relative clause so that verbsubject rather than subject-verb order holds. ${ }^{9}$ In these subject-inverted object relatives the tonal strategy is, on the face of it, still unacceptable $(8 \mathrm{c})$. Notice that the subject-inverted relative in (8b), without the low tone relative marker nor the segmental relative marker, still retains relative interpretation on a par with (7a).

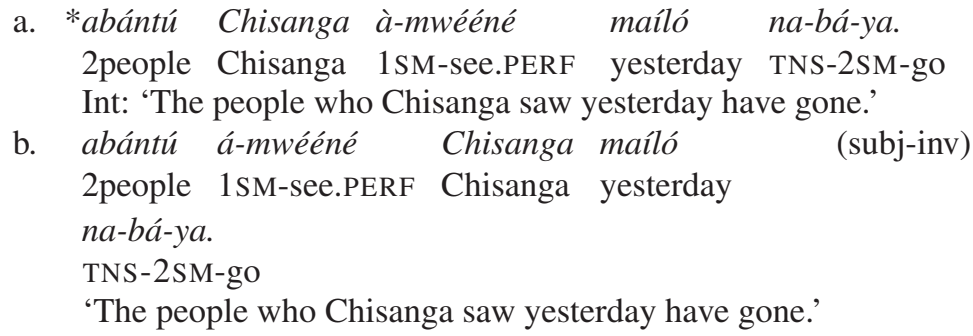

9. See Demuth and Harford (1999), Harford and Demuth (1999) for discussion of subjectinverted object relatives. 


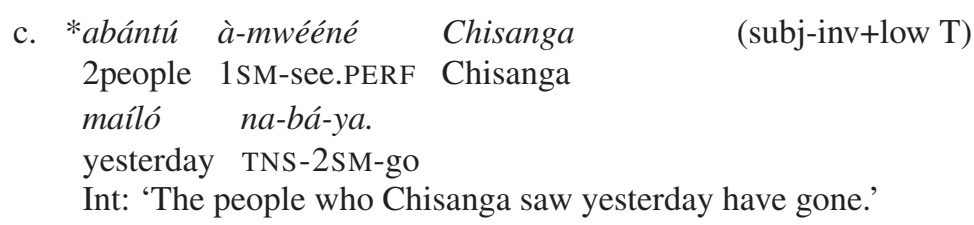

The only possibility of using the tonal strategy in object relatives is when the two arguments of the verb come from the same noun/agreement class. In addition to this, the relative must involve subject-inversion. Consider in this respect the subject-inverted object relative in (9a), where the two arguments umúluméndo 'boy' and Chisanga are from class 1. In this case, when the relative marker úo is omitted, a relative reading fails to hold, and the sentence must rather be interpreted as a simple sentence $(9 b)$. The only way to recapture the relative interpretation, in the absence of a segmental marker, is by using the tonal strategy, i.e., by inserting low tone on the subject agreement marker (9c). ${ }^{10}$

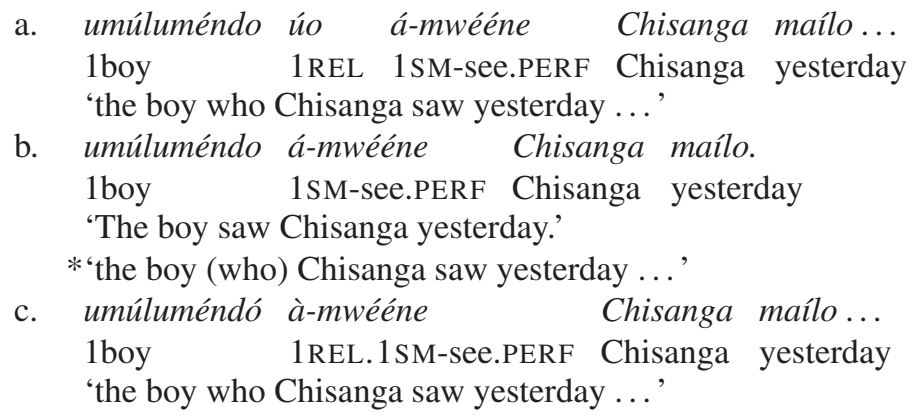

Notice that just like in subject relatives, the tonally marked object relative in (9c) induces a restrictive interpretation manifested in conjoint high tone on the head noun.

Without subject-verb inversion in the relative clause, the tonal strategy remains unavailable, even when the two arguments of the verb are from the same noun/agreement class. Consider (10).

a. umúluméndó úo Chisanga á-mwééne maíló ... 'the boy who Chisanga saw yesterday...'

10. Sentence (9c) is ambiguous between a subject and object relative reading that relies on context for disambiguation. The subject relative interpretation of the sentence would be: 'The boy who saw Chisanga yesterday ...'. 
b. umúluméndó Chisanga á-mwééne maíló ...

'the boy (who) Chisanga saw yesterday ...'

* The boy saw Chisanga yesterday'

c. *umúluméndó Chisanga à-mwééne maíló ...

Int: 'the boy who Chisanga saw yesterday ...'

(10a), the non-inverted counterpart of (9a), is segmentally marked. Omitting the relative marker in (10b) still retains the relative interpretation. Using the low tone strategy in this instance yields ungrammaticality in (10c).

This patterning of object relatives is not so surprising if we consider that the tonal strategy and the segmental marking of relatives are in complementary distribution. An additional dimension, lacking in subject relatives, is added to this complementary distribution in object relatives. While the omission of a relative marker is impossible in subject relatives, this is possible with the retention of a relative interpretation in object relatives. This means that in all cases where the relative marker is omitted in object relatives, the tonal strategy cannot be used, as such clauses already have a relative interpretation. This explains the absence of the tonal strategy in $(8 \mathrm{a}, 8 \mathrm{c}, 10 \mathrm{c})$. If, on the other hand, we try to derive an object relative by the tonal strategy from a simple sentence such as (9b), then this is possible (9c). The absence of a segmental marker in object relatives can therefore not be replaced by a tonal strategy because the clauses involved already have a relative interpretation. We can in this sense treat the tonal strategy in object relatives as involving disambiguation in situations where under subject inversion, a relative gets reinterpreted as a simple sentence because agreement on the verb can correspond to either the subject or the object when the two are from the same agreement class. In addition, in the inverted case, word order supports the simple sentence interpretation as long as subject marking is not decisive (compare $9 \mathrm{~b}$ and $10 \mathrm{~b}$ ).

Thus, in object relatives, the segmental strategy is used with the option of omitting the relative marker. When the relative marker is present, the relative can co-occur with both a head noun that bears conjoint high tone and one that does not. In contrast, when the relative marker is omitted, conjoint high tone must be present. In the last resort cases when the tonal strategy can be used in object relatives, the conjoint high tone must also be present, making a restrictive interpretation mandatory.

\subsection{Relative marking in headless relatives}

Headless relatives in Bemba have the typical definite interpretation of a headless relative (see, Grosu and Landman 1998). However, they do not have the 
free relative interpretation associated with the English counterpart whoever ${ }^{11}$

As illustrated in (11), headless relatives can be formed with a segmental marker for both headless subject (11a) and object (11b) relatives. Headless relatives generally tend to be restrictive despite the absence of a preceding conjoint high tone, which we have treated as indicative of restrictive interpretations.
a. á-bá-shipa béékala muZambia. 2REL-2SM-brave 2sM.live 18LOCZambia 'those who are brave live in Zambia.'
b. úo á-mwééne Chisanga maíló na-á-fika. 1REL 1SM-see.PERF Chisanga yesterday TNS-1SM-arrive 'the one who Chisanga saw yesterday has arrived.'

The tonal strategy cannot be used to mark headless relatives in either subject or object relatives, as the ungrammaticality of $(12 \mathrm{a}, \mathrm{b})$ and $(13 \mathrm{a}, \mathrm{b})$ shows, respectively.
a. *bà-shipa béékala muZambia.
2REL.2SM-brave 2SM.live 18Zambia
'Those who are brave live in Zambia.'
b. *à-ishílé maíló ni Mutale.
1REL.1SMcome.PERF yesterday COP Mutale
'The one who came yesterday is Mutale.'
a. *à-mwééne Chisanga maíló na-á-fika.
1SM-see.PERF Chisanga yesterday TNS-1SM-arrive
'Who Chisanga saw yesterday has arrived.'
b. *Chisanga à-mwééne maíló na-á-fika.
Int: 'Who Chisanga saw yesterday has arrived.'

The restrictive interpretations of (11) would be unexpected if restrictives were marked by the low tone morpheme, which, as seen in (12)-(13), cannot be used in headless relatives. As already pointed out, the matter can also not be resolved by the conjoint high tone on the head noun since headless relatives necessarily lack a head. I will show that the matter can be tackled by taking

11. To express the free relative interpretation, a quantificational element such as bonse 'all' has to be used, as shown below:

(i) na-ali-temwa bonse ábo a-béésa.

1SG.SM-TNS-love all 2DEM 2REL-2SM.come

Lit: 'I like all those who come.'/'I like everyone who comes.'

'I like whoever comes.' 
recourse to similarities between the phonological phrasing of restrictives, in general, regardless of whether they are tonally or segmentally marked.

\subsection{Summary of relative marking strategies}

It has been shown that relative marking for subject, object and headless relatives in Bemba can be viewed along three dimensions. Whether both the segmental and tonal strategy can be used, whether the two strategies allow both restrictive and non-restrictive interpretations, and whether the relative marker can be omitted. The facts for the three relative clause types are summarized in the table in (14).

\begin{tabular}{|c|c|c|c|c|c|c|}
\hline & \multicolumn{2}{|c|}{ segmental } & \multicolumn{2}{|c|}{ tonal } & \multicolumn{2}{|c|}{ rm omission } \\
\hline & restr. & non-restr. & restr. & non-restr. & restr. & non-restr \\
\hline subject & $\checkmark$ & $\checkmark$ & $\checkmark$ & $x$ & $x$ & $x$ \\
\hline object & $\checkmark$ & $\checkmark$ & $\checkmark$ & $x$ & $\checkmark$ & $x$ \\
\hline headless & $\checkmark$ & $x$ & $x$ & $x$ & $x$ & $x$ \\
\hline
\end{tabular}

Thus, while for segmentally marked relatives, both restrictive and non-restrictive interpretations can hold for subject and object relatives, only a restrictive interpretation can hold for the tonal strategy. Headless relatives in contrast to the other two relative types can never be non-restrictive nor be marked by tone. Headless relatives and subject relatives pattern together in disallowing the omission of the relative marker while object relatives freely allow such omission, in which case, a restrictive interpretation must hold.

In the next section, I analyze the phonological phrasing associated with these relative marking patterns against possible syntactic analyses of relative clauses. I develop an analysis where the favored syntactic analysis is one that maximizes the correspondence between phonology and syntax.

\section{Phonological phrasing and the phonology-syntax interface}

As already pointed out, the phrasing in relative clauses reveals that a restrictive interpretation holds whenever the head noun and the relative clause are phrased together. Tonally marked relatives, which coincide with restrictives, therefore never have a MaP boundary between the head noun and the relative clause (indicated by conjoint high tone on the head noun). Consider in this respect (15), where the phonological phrasing in (15b) as opposed to (15a) is ungrammatical for tonal relatives. $(15 \mathrm{c}-\mathrm{d})$ contrast restrictive versus non-restrictive relatives, 
respectively, for segmentally marked relatives by a difference in phrasing that is indicated by the presence versus the absence of the conjoint high tone on the head noun, respectively.
a. (abáBembá bà-shipa) $)_{\mathrm{MaP}}$ (beekala (tonal REL) 2Bembas 2REL.2SM-brave 2sM.live muZambia) $)_{\mathrm{MaP}}$
18LocZambia
'Bembas who are brave live in Zambia (while those who aren't brave live elsewhere).'
b. *(abáBemba $)_{\mathrm{MaP}}$ (bà-shipa) $)_{\mathrm{MaP}}$ (beekala muZambia $)_{\mathrm{MaP}}$
c. (abáBembá ábá-shipa $)_{\mathrm{MaP}}$ (beekala (segmental REL) muZambia $)_{\mathrm{MaP}}$
d. (abáBemba) $)_{\mathrm{MaP}}$ (ábá-shipa) $)_{\mathrm{MaP}}$ (beekala (segmental REL) muZambia $)_{\mathrm{MaP}}$
'Bembas, who are brave, live in Zambia' (All Bembas are brave)

The ungrammaticality of (15b), despite the final low tone on the head noun, indicates a restriction specific to the tonal relative marker; it must be phonologically phrased with the preceding constituent. This can be formulated as a phonological constraint that disallows the relative low tone from occurring at the left edge of a phonological phrase.

As has already been illustrated, the same phrasing asymmetries hold for object relatives. (16a) and (16b) differ in reading, although a segmental relative marker is used to mark both. The former has a restrictive relative interpretation while the latter has a non-restrictive interpretation. (16c) indicates the tonal strategy with phonological phrasing necessarily for restrictives and further indicates that if the head noun was not phrased together with the verb, the sentence would be ungrammatical (16d). ${ }^{12}$ Examples are repeated from (6)(7).

(16) a. (abántú ábo Chísanga á-mwééne maílo $)_{\mathrm{MaP}}(\text { na-bá-ya })_{\mathrm{Map}}$ 'The people who Chisanga saw yesterday have gone.'

b. (abántu) $)_{\mathrm{MaP}}(a ́ b o \text { Chísanga á-mwééne maílo })_{\mathrm{MaP}}(\text { na-bá-ya })_{\mathrm{MaP}}$ 'The people, who Chisanga saw yesterday, have gone.'

c. (umúluméndó à-mwéené Chisanga maílo) MaP

'The boy who Chisanga saw yesterday.'

d. *(umúluméndo $)_{\mathrm{MaP}}(\text { à-mwéené Chisanga maílo })_{\mathrm{MaP}}$

12. This was tested using PRAAT (Boersma and Weenink 2005) generated sentences, where the head noun ends in a low tone and is phrased separately from the verb in tonally marked object relatives. These were at best judged as of unclear import. 
Recall that in object relatives it is possible to optionally omit the segmental relative marker and a relative clause reading will still obtain. The phrasings in these cases, both with and without subject inversion, are given in (17a-b). In both cases, the head noun bears conjoint high tone and must be phrased together with the relative clause, and there is a mandatory restrictive reading of the relative clause. If the head noun and the verb are not phrased together, as in $(17 \mathrm{c})$, a relative interpretation cannot be obtained.
a. (abántú Chisanga á-mwééne maílo $)_{\mathrm{PPh}}(\text { na-bá-ya })_{\mathrm{PPh}}$
b. (abántú á-mwééne Chisanga maílo $)_{\mathrm{PPh}}(\text { na-bá-ya) })_{\mathrm{PPh}}$ 'The people that Chisanga saw yesterday have gone.'
c. *(abántu $)_{\mathrm{PPh}}(\text { Chisanga á-mwééne maílo })_{\mathrm{PPh}}(\text { na-bá-ya })_{\mathrm{PPh}}$
Int: 'The people, who Chisanga saw yesterday, have gone.'

This implies that object relatives without an overt segmental relative marker can never have a non-restrictive reading. This is further confirmed by the fact that proper names cannot act as head nouns in these cases.

The conclusion is thus that a restrictive relative clause, be it tonally marked or marked by a segmental relative marker, requires that the head noun and the relative clause be in the same phonological phrase. Conversely, a nonrestrictive relative clause forms a separate MaP from the head noun.

\subsection{Implications for syntactic structure}

For an optimal mapping between phonology and syntax, the best syntactic analysis would be one where the phrasing that differentiates restrictives from nonrestrictives, as illustrated above, can also follow (at the appropriate level) from the syntactic structure. If we take relative clauses to be CPs, then an analysis in which a relative clause $\mathrm{CP}$ is phrased together with the head noun that it modifies, would be preferable for the characterization of restrictives in Bemba. I will here explore two highly simplified competing analyses of restrictives and show that the selection of one of these follows directly from phonological phrasing.

The contrast for restrictives will be between a standard structure (18a) (cf. Peranteau, Levi and Phares 1972) and the Kaynian structure (18b) following Kayne (1994). ${ }^{13}$ The crucial difference between the two is that under the standard view, the head noun is outside of the CP that is the relative clause, i.e., the $\mathrm{CP}$ is right-adjoined to the head noun NP. Kayne's analysis, on the other hand, employs head-raising where the head noun of the relative clause remains within the CP. There is no adjunction structure in this case. ${ }^{14}$

13. There are variations of the Kaynian structure, which will not be discussed here. See Bianchi (2000) for an exposition. 
(18)

a.

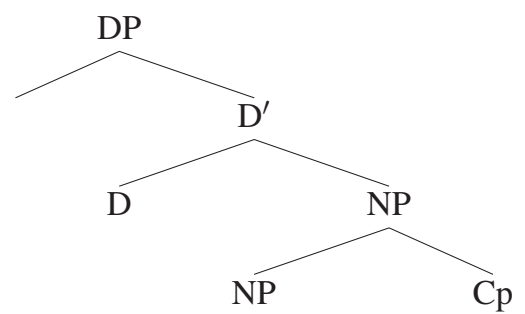

[head noun]

b.

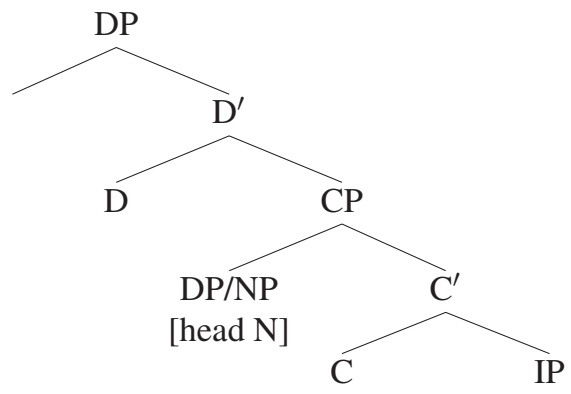

As we have already pointed out, the relevant difference between the two analyses of restrictives for Bemba is where the CP boundary falls. (19) presents the relevant structures for an object relative.
a. abántú ábo n-a-mwééne
maíló...
2people 2REL 1SM-TNS-see.PERF yesterday 'the people who I saw yesterday ...'
b. [dp [np abántú [cp ábo n-a-mwééne maíló ... ]]]
c. [dp [cp abántú ábo n-a-mwééne maíló ... ]]

(standard)

(Kaynian)

As indicated by (19b), within the standard analysis, the CP boundary falls right before the relative marker ábo, while in the Kaynian analysis, the CP boundary is right before the head noun abántú. If a CP boundary is to coincide with a phonological phrase boundary, then the Kaynian analysis is a better representation of the phonological phrasing facts, as presented in the schematic comparison between the two analyses in (20).

a. Standard analysis

[dp [np=MaP [np Bemba's] [cp=MaP that are brave... ]]]

mbox

(restrictive relative)

14. It is not easy to say exactly where the relative clause begins in a Kaynian analysis. For whrelatives, the relative pronoun is in SpecCP, while for that-relatives, the complementizer that is still in $\mathrm{C}^{0}$. 
b. Kaynian analysis

$$
[\mathrm{dp}[\mathrm{cp}=\mathrm{MaP} \text { Bemba's that are brave ...]] (restrictive relative) }
$$

The standard analysis in (20a) has two phonological phrases because the head noun is syntactically outside of the $\mathrm{CP}$, which itself coincides with a MaP edge. In contrast to this, the Kaynian analysis only has one MaP, while retaining the edge of the $\mathrm{CP}$ as coinciding with a MaP edge. This follows directly from the head raising analysis assumed. We can thus select the Kaynian analysis as most satisfactory for restrictives because it additionally adheres to the phonological phrasing. In this sense, a head noun that is syntactically internal to a $\mathrm{CP}$, forms one phonological phrase with the relative clause.

For non-restrictives, the standard and the Kaynian analyses make identical correct predictions, namely, two phonological phrases following from an adjoined structure (a CP is adjoined to a DP) for appositives (as also presented in Demirdache 1991). This is schematized in (21). In this case, a head noun that is syntactically external to the relative clause $\mathrm{CP}$ does not form a MaP with the relative clause.
a. Standard analysis
[dp [dp=MaP Bemba's] [cp=MaP that are brave ...]]
b. Kaynian analysis
[dp [dp=MaP Bemba's] [cp=MaP that are brave ... ]]
(non-restrictive relative)
(non-restrictive relative)

The phonological phrasing facts thus favor a syntactic analysis that transparently models the opposing phrasing patterns between restrictives and nonrestrictives.

In light of these analyses, we can consider headless relatives, which despite lacking an overt head can still be interpreted restrictively, as having a syntactic analysis parallel to the Kaynian one adopted for restrictives. ${ }^{15}$ In this case, we can simply assume a prosodically empty pronoun to be in SpecCP in headless relatives, as illustrated in (22).
a. á-bá-shipa
na-bá-ya
PPF-2SM-brave TNS-2SM-go
'Those who are brave have gone.'
b. [dp [cp pro [c' ábáshipa na-bá-ya]]]

15. The syntactic analysis of headless relatives is a controversial topic. Note that what is posited here may not extend to free relatives in English since the reading of headless relatives in Bemba is not identical to free relatives. 
Example (22b) allows for a single MaP with the $\mathrm{CP}$ edge coinciding with a MaP edge.

Thus, taking the $\mathrm{CP}$ as a syntactic head relevant for phrasing, and given the phonologically determined phrasing facts of Bemba, a Kaynian analysis provides us with the best mapping between syntax and phonology. In the next section I present a sketch of a possible analysis of this mapping. The use of Optimality Theory and its system of ranked and violable constraints is not central to the point at hand, but is used for expository purposes only.

\subsection{An interface account of the syntax-phonology mapping}

Two phonological effects in the observed facts must be accounted for by any analysis. The first is that the distinction between restrictives and non-restrictives follows from phrasing indicated by conjoint tone on the head noun. The second is the restriction seen on the use of the tonal relative marker, particularly its absence from headless relatives. Following assumptions of Generalized Alignment (Prince and Smolensky 2004; McCarthy and Prince 1995), the former will be accounted for using a constraint that requires the right edges of phonological phrases to be signaled by low tone as given in (23). In this case, the conjoint high tone will never have a phonological phrase boundary following it. The latter effect will be captured by a constraint that requires left edges to be aligned with a high tone, as given in (24). ${ }^{16}$ This is a way of ensuring that the relative low tone is never at the left edge of a phonological phrase.

\section{(23) Align(MaP R, Low R,}

Align the right edge of a major phrase with a low tone.

Align(MaP L, High L)

Align the left edge of a major phrase with a high tone.

Example (23) represents the situation in non-restrictives, where no conjoint high tone appears on the head noun when it is phrased separately from the relative clause. Restrictives will escape the violation of this constraint by phrasing a head noun bearing conjoint high tone with a following complement. (24) accounts for the absence of the tonal strategy in non-restrictives and for headless relatives as high tone being preferred over low tone at the left edges of MaPs.

In relating these phonological constraints to syntax, we must capture the fact that the relevant left edge that phonology refers to in (24) coincides with a $\mathrm{CP}$ in

16. Other constraints interacting with Align-MaPL, High-L will derive low tone in phrase-initial position in cases where it occurs. Otherwise, the constraint could be formulated to not affect lexical low tones. I leave out the discussion of these issues, as they are only tangential to the point at hand. 
syntax. Since other XPs are irrelevant for the restrictive-non-restrictive distinction, it is necessary to make specific reference to a CP. In this case, alignment constraints are best understood as constraints of the interface between phonology and syntax and not just as operating at PF when categorical information is obliterated. ${ }^{17}$ To achieve this end, we can specify the general constraint of Selkirk (1995) in (25) to a more specific constraint that refers to CPs, as in (26).

\section{a. ALIGN-XP, R}

For each XP there is a $\mathrm{P}$ (phonological phrase) such that the right edge of XP coincides with the right edge of $\mathrm{P}$.

b. ALIGN-XP, L

For each XP there is a $\mathrm{P}$ such that the left edge of XP coincides with the left edge of $P$.

\section{Align-CP, L}

For each $\mathrm{CP}$ there is a $\mathrm{P}$ such that the left edge of that $\mathrm{CP}$ coincides with the left edge of $P$.

If we assume that the MaP in (26) also coincides with an intonational phrase, we can avoid the violation of the Lexical Category Condition (LCC), which bars functional projections like CP and IP from being subject to alignment constraints (Selkirk 1995). ${ }^{18}$

I will, in addition, use standard WRAPXP constraints (Truckenbrodt 1999) as constraints regulating phonological phrasing. The REALMORPH (realize morpheme) constraint will also be relevant to ensure that a relative marker is realized in relatives. NONRECURSION will also be assumed following Selkirk (1995). These additional constraints are defined in (27).

$$
\begin{aligned}
& \text { a. WRAP-XP (Truckenbrodt 1999) } \\
& \text { Each XP is contained in a phonological phrase. } \\
& \text { b. REALMORPH } \\
& \text { A relevant morpheme must be realized. }
\end{aligned}
$$

17. I thank an anonymous reviewer for discussion on this point. The reviewer also suggests that another possibility, which would avoid interface constraints, would be to treat the lexical $\mathrm{XP}$ dominating the relative $\mathrm{CP}$ as the one relevant for phonological phrasing. In this case, a lexical XP would mark the left edge of the MaP, and CPs would remain invisible. This would mean, however, that both the Kaynian and the standard analyses, in which a DP dominates the relative clause $\mathrm{CP}$, would have the same MaP structure. This means phonology would fail to tease apart the quite radically different syntactic structures.

18. Truckenbrodt (2005) also pursues the possibility of intonational phrases coinciding with CPs. $\mathrm{He}$ extends the family of Wrap-XP constraints to include Wrap-CP, which requires each $\mathrm{CP}$ to be contained in an intonational phrase. 
c. NONREC (Selkirk 1995)

A P constituent must not contain another $\mathrm{P}$ constituent of the same level.

Align-MaPL, High-L and AlignCP-L are the highest ranked constraints with no ranking between them. The former makes it less preferable to begin a MaP with a low tone. This is crucial in barring the relative low tone morpheme from occurring at the left edges of MaPs. Align-MaPR, LowR and WRAP$\mathrm{XP}$ are lower ranked and unranked with respect to each other, with the former favoring MaPs that end in low tone. This ensures that the conjoint high tone is never immediately followed by a MaP boundary. Consider the interaction of these constraints in tableau (28) for restrictive relatives under the given ranking. (NONREC is not shown in the tableaux).

Align(MaPL, HighL), AlignCP-L $\gg$ WraP-XP, Align(MaPR, LowR) $\gg$ REALMORPH

Restrictives: ábábémbá bà-shipa...

'Bembas who are brave...'

\begin{tabular}{|c|c|c|c|c|}
\hline ábabémba bá-shipa.. & $\begin{array}{r}\mathrm{AL}-\mathrm{AL}- \\
\mathrm{PL}, \mathrm{HL} \mathrm{C}_{\mid} \mathrm{CPL}\end{array}$ & $\begin{array}{c}\text { WRAP } \\
\text { XP }\end{array}$ & $\begin{array}{l}\mathrm{AL}- \\
\mathrm{P} \mathrm{PR}, \mathrm{LR}\end{array}$ & RMPH \\
\hline a. $\left([a ́ b a ́ B e m b a]_{N P}\right)_{\operatorname{map}}\left([\text { bà-shipa }]_{\mathrm{CP}}\right)_{\mathrm{Map}}$ & $* !$ & & 1 & \\
\hline b. ([ábáBembáa $\left.]_{\mathrm{NP}}\right)_{\operatorname{map}}\left([\text { bá-shipa }]_{\mathrm{CP}}\right)_{\operatorname{map}}$ & & & $* !$ & * \\
\hline c. $\left([a ́ b a ́ B e m b a]_{N P}\right)_{\operatorname{map}}\left([\text { bá-shipa }]_{\mathrm{CP}}\right)_{\operatorname{map}}$ & 1 & & 1 & $* !$ \\
\hline d. $\left(\left[[a ́ b a b e ́ m b a]_{N P} \text { bà-shipa }\right]_{C P}\right)_{\text {map }}$ & 1 & & & \\
\hline 画e. ([[ábabémbál $]_{\mathrm{NP}}$ bà-shipa $\left.]_{\mathrm{CP}}\right)_{\mathrm{map}}$ & $T$ & & $T$ & \\
\hline
\end{tabular}

Candidates $(28 \mathrm{a}-\mathrm{c})$ represent the phrasing we would get under the standard analysis where the head noun is external to the relative clause $\mathrm{CP}$ and the NP and $\mathrm{CP}$ are therefore in independent MaPs. Candidate (28a) fatally violates the highly ranked Align-MaPL, High-L by having the relative low tone at the left edge. Candidates (28b) and (28c) avoid violation of high ranking Align-MaPL, High-L by having no low tone at the left edge, but as a result, they violate lower ranked RealMorph that requires a relative marker to be present in relatives. (28b) additionally fatally violates Align-MaPR, Low-R by having conjoint high tone on the head noun followed by a MaP boundary. A candidate phrasing both the NP and the $\mathrm{CP}$ in one MaP would violate high ranked AlignCP-L.

Candidates (28d) and (28e) give phrasing under a Kaynian analysis and differ only in that (28d) lacks conjoint high tone on the head noun. For this reason, candidate (28d) violates Align-MaPR, Low-R by having no MaP boundary after a low tone, allowing (28e) to emerge as the winner. The phonological phrasing thus favors a syntactic analysis that treats the head noun as internal to the CP. 
Restrictive object relatives with the segmental relative marker are treated in the same fashion. Recall, however, that in object relatives the relative marker is always optional and would in these cases violate RealMorph, so that examples parallel to (28c) could wrongly emerge as winners. In this case, we would have to consider a higher ranked constraint that would prevent this outcome. A possibility is a faithfulness constraint that requires input conjoint high tone to be faithfully parsed in the output. Since object relatives with an omitted relative marker always have a restrictive interpretation, we can treat them as having input specified conjoint high tone.

Tableau (29) illustrates non-restrictives, which, as seen in earlier discussion, involve separate phrasing of the head noun and the relative clause for both the Kaynian and the standard analyses. Despite having the desired MaP structure, candidate (29c) loses because it uses the tonal strategy rather than a segmental relative marker, thereby fatally violating highly ranked Align-MaPL, High-L. Candidate (29d) that phrases the NP and the CP in one MaP also loses by fatally violating AlignCP-L because it fails to align the CP with the left edge of a MaP. Candidate (29b) fares quite well in comparison to the winner (29a) but loses because it aligns the conjoint high tone with the right edge of a MaP.

\begin{tabular}{|c|c|c|}
\hline abáBemba ábá-shipa ... & $\begin{array}{|r:|}\mathrm{AL}^{\mathrm{A}} \mathrm{AL}- \\
\mathrm{PL}, \mathrm{HL} / \mathrm{CPL} \\
\end{array}$ & \begin{tabular}{c|c|} 
WRAP- & AL- \\
XP & IPR,LR
\end{tabular} \\
\hline W a. $\left([a ́ b a b e ́ m b a]_{\mathrm{dp}}\right)_{\mathrm{map}}\left([a ́ b a ́-s h i p a \ldots]_{\mathrm{CP}}\right)_{\mathrm{map}}$ & 1 & 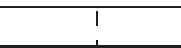 \\
\hline b. $\left([a ́ b a b e ́ m b a ́]_{\mathrm{dP}}\right)_{\operatorname{map}}\left([a ́ b a ́-\text { shipa } \ldots . . .]_{\mathrm{CP}}\right)_{\operatorname{map}}$ & & $* !$ \\
\hline c. $\left.([a ́ b a b e ́ m b a ́]]_{\mathrm{dP}}\right)_{\operatorname{map}}\left([\text { bà-shipa .... }]_{\mathrm{CP}}\right)_{\mathrm{map}}$ & $* !$ & 1 \\
\hline d. ([ábabémbá $\left.]_{\mathrm{dp}}[\text { ábá-shipa .... }]_{\mathrm{CP}}\right)_{\mathrm{map}}$ & $* !$ & t \\
\hline
\end{tabular}

For non-restrictives then, an appositive structure where the DP is a sister to the relative clause CP (as in, Demirdache 1991), provides an analysis that is compatible with phonological phrasing. Under such an analysis, the low tone morpheme can never be used to mark non-restrictives, as it would occur at the left edge of a MaP violating high ranked Align-MaPL, High-L.

Compared to the analysis of restrictive and non-restrictive relatives, headless relatives are different because they lack an overt head. In terms of syntactic structure, we have treated headless relatives on a par with restrictives under a Kaynian analysis. However, recall that they share a crucial similarity with non-restrictive relatives; they cannot be formed using the tonal strategy. This follows directly from the absence of a head noun, as it entails violation of Align-MaPL, High-L if the low tone morpheme is used. This quite trans- 
parently explains the parallel, with respect to the absence of the tonal strategy, between headless relatives and non-restrictives. In this case, the analysis of headless relatives follows straightforwardly from the given constraint ranking, as illustrated in tableau (30).

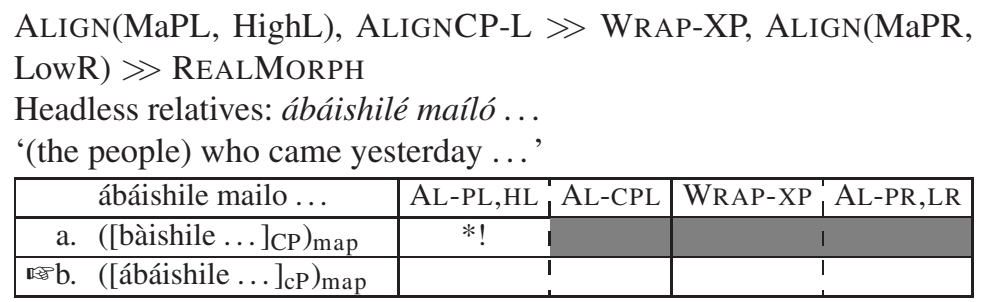

The two candidates (30a) and (30b) have identical phrasing and differ only in the relative marker used. As opposed to the relative low tone in (30a), the segmental relative marker in (30b) escapes violation of high-ranked Align-MaPL, High-L and therefore emerges as the winner. By virtue of not having an overt head, the relative clause of the winning candidate (30b) is contained in a single $\mathrm{MaP}$ and gets a restrictive interpretation. This provides further evidence that phonological phrasing, rather than the use of the tonal morpheme, for example, is what induces restrictive versus non-restrictive interpretations of relatives.

We can thus conclude that for the mapping between phonology and syntax for restrictive relatives, the Kaynian analysis makes the best phonological predictions. For non-restrictive relatives, an appositive structure as in Demirdache (1991) coincides best with phonological phrasing. Finally, for headless relatives, a Kaynian analysis where the relative clause is within a single MaP, in line with the restrictive nature of headless relatives, provides an optimal correspondence between phonology and syntax. This phrasing also explains the inability of headless relatives to use the tonal strategy in a manner akin to nonrestrictives.

A final point I would like to turn to is the nature of the syntax-phonology relation. In the model of the grammar as presented in Chomsky (1981 et seq.) the syntactic module with the operations select, merge and move deriving syntactic structures is prior to PF (the phonological component), which comes after spell-out. This necessarily implies that phonology can have no direct influence on syntax but rather phonology deals with the output of syntax. In this sense, prosodic structure in the prosodic hierarchy provides intermediate structure that channels the interface between the two modules. The influence of phonology on syntax is, as such, limited to disambiguation scenarios or involves preference choices over independently derived syntactic structures, after the computation of syntax is complete (cf., Golston 1995; Zwicky and Pullum 1986; 
Guasti and Nespor 1999). ${ }^{19,20}$ In this regard, phonological phrasing in Bemba relatives, aids in the choice between two well-formed syntactic structures.

In the following section, I pursue an alternative (perception-based) model of the grammar in Dynamic Syntax (DS) (Kempson, Meyer-Viol and Gabbay 2001; Cann, Kempson and Marten 2005) where a direct influence of phonology on syntax is possible. In this model, syntax and phonology are not regarded as encapsulated and can therefore enjoy a feeding relation. ${ }^{21}$ This is in line with ideas developed in Government Phonology where the primary function of phonology is to act as a parsing device that aids speakers in, on the one hand, lexical access (Kaye 1989; Kula 2002) and in building structured semantic representations on a left-to-right basis (Kaier 2005, in preparation; Marten and Kula in preparation), on the other. The idea is simply that syntactic structures are built on-line and phonological information, such as the conjoint tone seen in Bemba relatives, provides salient cues that aid speakers in syntactic structure building and the eventual retrieval of the intended message of the utterance.

\section{Modelling syntax-prosody interactions in Dynamic Syntax}

Dynamic Syntax (Kempson, Meyer-Viol and Gabbay 2001; Cann, Kempson and Marten 2005) is a syntactic model that constructs syntax from a parsing perspective, where information from words is used to build increasingly complex semantic representations. ${ }^{22}$ Similar to Categorial Grammar, Dynamic Syntax employs semantic types that constrain the combination of partial structures, and various forms of semantic and structural underspecification are assumed. From this perspective, phonological and prosodic information can be seen as guiding and/or restricting steps in the parsing process. In particular, as I will show below, tonal marking in relative clauses can be seen as imposing

19. More recently, some researchers have proposed to circumvent this problem by assuming postspell-out 'PF-movement' (e.g., Benmamoun 2000). However, even under this model, phonology has no impact on the completed syntactic structure that is fed to LF.

20. The possibility of producing ungrammatical outputs is reduced with multiple spell-outs at different phases (vP, IP, CP) in the Minimalist Program (Chomsky 2001; Hornstein, Nunes and Grohmann 2005). Phases also provide a possibility for the intermediate influence of phonology on the syntactic structure derivation if phonology (the PF component) is part of the output conditions that evaluate phases. In these cases as well, though, PF conditions would apply after spell-out at each phase.

21. Although syntax and phonology are not encapsulated in DS they are still distinct systems with independent vocabularies.

22. Although the perspective adopted is related to parsing, the Dynamic Syntax model is not a parsing model in the traditional sense, as crucially, Dynamic Syntax does not presuppose an independently defined competence model. Rather, the claim is that the dynamics of building semantic representations is all there is to syntax. 
restrictions on the construction of so-called LINK structures, which are used to analyze relative clauses, and so directly encode how restrictive and nonrestrictive relatives are built on-line. Before turning to the details of the analysis, however, I provide a brief outline of a syntactic derivation in Dynamic Syntax (DS) in the next section.

\subsection{Syntactic derivations in DS}

At the outset of any DS derivation, a minimal tree is assumed with just one node, and no branches. The node is annotated with $\operatorname{Tn}(0)$, indicating that it is the root node, and ?Ty(t), indicating that at this node a requirement holds for an expression of type Ty(t), that is, a proposition. This expresses a hearer's justified expectation for information of a propositional type, which may interact with currently held assumptions (cf. Sperber and Wilson 1995). The diamond indicates that the node is the current node (trivially so in (31), since there is only one node so far):

$$
\operatorname{Tn}(0), ? \operatorname{Ty}(\mathrm{t}), \diamond
$$

However, since in most cases, not the whole proposition is communicated at once, syntactic rules license the introduction of subtasks in this situation: ${ }^{23}$

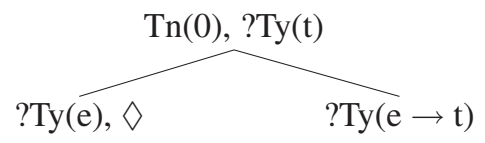

The rationale behind this move is that the satisfaction of both subtasks leads automatically to the satisfaction of the overall goal, and that the subtasks may be easier to accomplish than the task at the root node. The fact that the argument node (on the left-hand side) becomes the current node, rather than the predicate node on the right, is a parametric value of SVO languages.

At this stage, the first lexical information is scanned. Let's take a string like Daudi likes Muna as the example sentence of this parse. Lexical information from the word Daudi is then the first information to be processed. Lexical information in Dynamic Syntax is modelled as procedural, and as interacting with the tree annotations directly: ${ }^{24}$

23. Phonological rules can also license the introduction of subtasks. It is in this way that phonological information will be seen to influence the syntactic derivation.

24. Tonal morphemes such as the low tone of relativization can also be represented as lexical items incorporating procedural tasks that can then guide the derivation. 


$$
\begin{array}{lll}
\text { 'Daudi' } & \text { IF } & \text { ?Ty(e) } \\
& \text { THEN } & \text { put(Fo(daudi'), Ty(e)) } \\
& \text { ELSE } & \text { abort }
\end{array}
$$

The IF statement in the lexical information from Daudi states that the word can be introduced into the derivation if there is a current node with a requirement ?Ty(e). If this is so, then at that node, 'Fo(daudi')' and 'Ty(e)' can be added. On the other hand, if Daudi is parsed and the current node does not have a requirement for $\mathrm{Ty}(\mathrm{e})$, the parse ends. In the case at hand, the condition of the IF clause is met, as the current node in (32) has a requirement for Ty(e), which the information from Daudi fulfils, and the tree can be developed further:

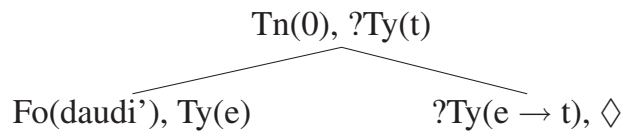

The next step is the expectation of the development of the predicate node, and the parsing of likes (ignoring tense and agreement for the moment). The actions of the THEN clause of like, specified in its lexical information, result in the building of a new predicate node, and a corresponding argument node with a requirement ?Ty(e), which becomes the current node:

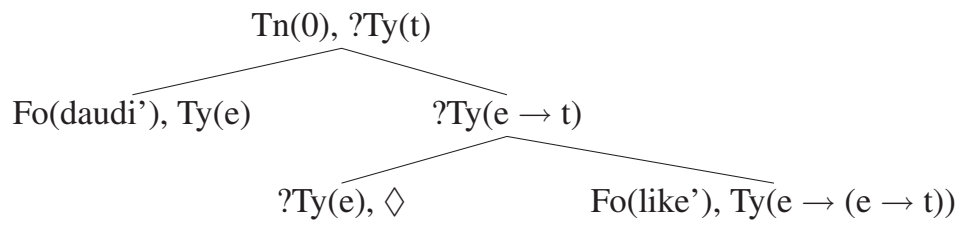

The next word is Muna, which comes with lexical information similar to that of Daudi, and can fulfil the requirement at the current node:

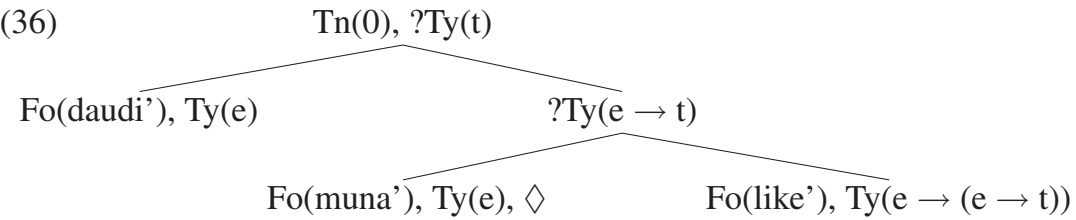

In the final tree of the derivation all the information established during the parse is accumulated by computing the assembled information upwards in the tree, driven by function-application over types, so that all requirements are fulfilled: 


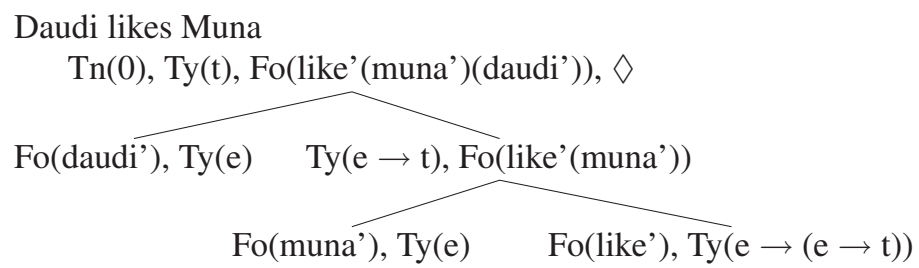

The final tree is the logical form associated with the string Daudi likes Muna. As this sample derivation shows, syntactic and lexical information combine to develop increasingly complex tree structures in an interaction between the establishment of requirements and their fulfilment by lexical information. During the final step, the accumulated information is combined to compute the eventual logical form. In this sense, the DS system provides a formal means to show how natural language syntax reflects the way humans are able to build complex semantic structures from a linear string of words.

\subsection{Building complex structures: Bemba relatives and phonology-syntax re- lations}

Relative constructions in DS are analyzed as involving LINK relations, which are launched from Ty(e) nodes and introduce a separate tree i.e., the relative clause. The relation between the head noun and the following relative, which is now in a new, separate tree, is retained by a requirement that the formula value of the head noun be part of the new tree. This is equivalent to requiring the presence of a relative marker that links the relative clause to the head noun. The information from the relative clause is collected at the node from which the LINK relation was launched and is then subsequently used in the construction of the eventual tree.

For Bemba relatives, the interesting issue is to see in what instances phonology licenses the launch of a LINK relation. Two issues are interesting in this respect. Firstly, the marking of relative clauses by the low tone morpheme, and secondly, the conjoint high tone indicating restrictive relatives. Let us begin with the latter.

As has already been mentioned, LINK relations that are used to characterize relative clauses are launched from Ty(e) nodes. These Ty(e) nodes are part of the invariable complex structure of nominal phrases illustrated in (38) for the head noun ábáBemba 'Bembas'. ${ }^{25}$

25. The quantifier in (38) is an iota term È, rather than a tau term, essentially introducing an unquantified set. 


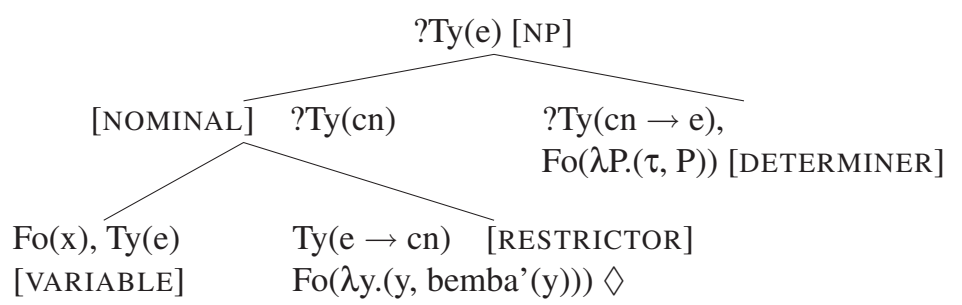

According to general DS rules, the pointer will move from its current position to its sister node (the variable node) so as to accumulate the information from the two daughter nodes at their mother node, where ?Ty(cn) holds. The nominal will then merge with the determiner information to give the full NP at the top node. In (38) a LINK relation can be launched from either the top Ty(e) node at [NP] or from the lower Ty(e) node at the variable node. Of importance here is that the nominal variable is analyzed as inhabiting its own tree node. This variable is restricted by the predicate in the restrictor node when the information from the two nodes combines. Under this reasoning, restrictive relatives are analyzed as LINK structures that are launched from the variable node, while non-restrictives are analyzed as LINKed from the top Ty(e) node.

For Bemba restrictives, the point is that the conjoint high tone provides information that the LINK relation should be launched from the lower Ty(e) node, in a scenario where the two Ty(e) nodes would otherwise be freely available. Just as syntactic rules were shown to provide subtasks for further tree building in (32), phonological rules, here phonological phrasing rules, provide instructions for the syntactic derivation. The crucial difference between restrictives and non-restrictives is therefore whether the LINK relation is launched after the whole information from the nominal structure has been completed (nonrestrictives) or not (restrictives). Snapshots of the relevant points in the derivation, that is, when the interpretation of the subject node is computed, make this difference clear: 
'Bembas who are brave...'

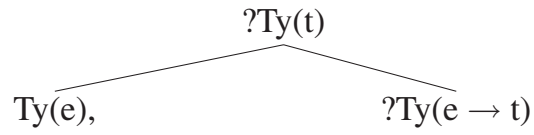

Fo((, x, bemba' $(x)) \&$ shipa(bemba)),

$\operatorname{Ty}(\mathrm{cn})$

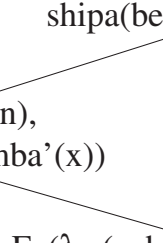

$$
\begin{gathered}
\mathrm{Fo}(\mathrm{x}), \operatorname{Ty}(\mathrm{e}) \quad \operatorname{Fo}(\lambda y .(\mathrm{y}, \mathrm{bemba}(\mathrm{y}))), \\
\operatorname{Ty}(\mathrm{e} \rightarrow \mathrm{cn})
\end{gathered}
$$$$
\text { ?Ty }(\mathrm{cn} \rightarrow \mathrm{e})
$$$$
\operatorname{Fo}\left(x, \operatorname{bemba}^{\prime}(\mathrm{x})\right) \quad \operatorname{Fo}(\lambda \mathrm{P} .(\mathrm{l}, \mathrm{P}))
$$

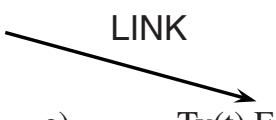

The non-restrictive reading in (39) involves a LINK structure from a node decorated with $\operatorname{Ty}(\mathrm{e})$ and $\mathrm{Fo}(\mathrm{l}, \mathrm{x}$, bemba' $(\mathrm{x}))$, that is, at a stage in the derivation when the quantificational structure of the NP ababemba 'Bembas' has already been computed: the nominal variable $\mathrm{x}$ is restricted by the predicate bemba'. To this node description, the LINK structure adds Fo(shipa'(bemba')). This means that a set of Bembas is contextually identified, and that of this identified set, it is true that they are brave. The information from the LINK structure thus adds additional information. In contrast, the restrictive relative reading involves the structure below: 
(40)

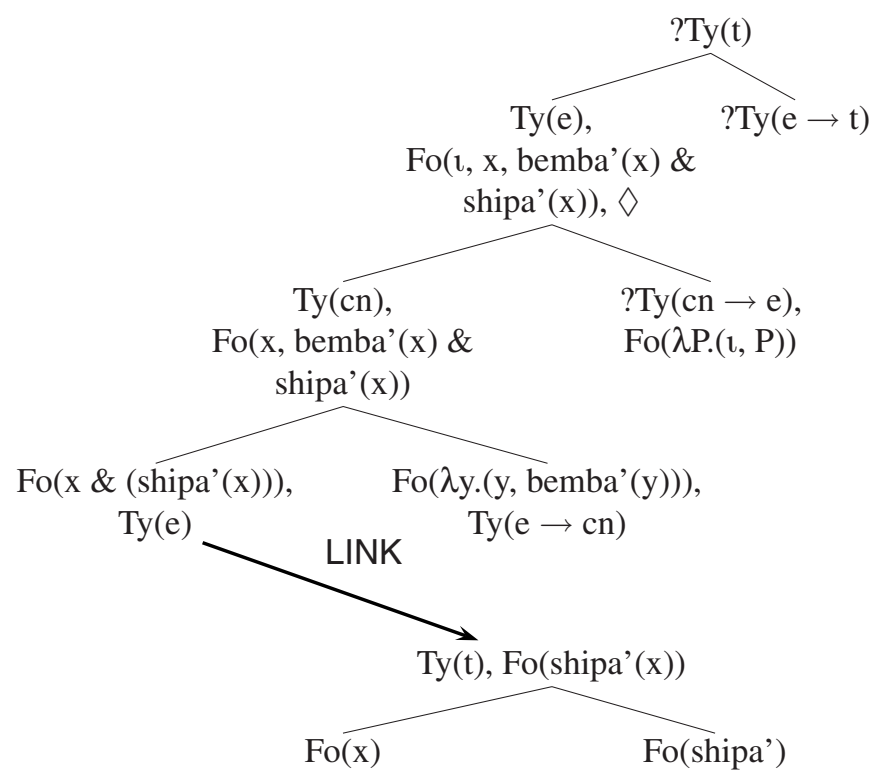

Here, the LINK structure is launched from the variable node, and thus the information from the LINK structure acts as restriction on the variable in the same way that the predicate bemba'(x) does. The information from the LINK structure is - as part of the restrictor of the variable - carried all the way up the tree to the node where the NP interpretation is computed. But this time, of course, the information from the LINK structure is part of the quantificational structure, not an addition to it. Thus, the relevant formula value $\mathrm{Fo}(\mathrm{l}, \mathrm{x}$, bemba'(x) \& shipa'(x)) identifies the set of x's that are both Bembas and brave: the restrictive reading.

Lets us now come to the low tone morpheme and consider what phonological information it provides in the syntactic derivation. Relative markers/pronouns are treated as lexical items in DS whose lexical entries specify the decoration of an unfixed node. An unfixed node is a node that can be created in the course of a derivation to be incorporated into a tree later in the derivation. ${ }^{26}$ The information in the unfixed node of relative markers gets merged in the position where the head noun is interpreted, i.e., in subject or object position. The low tone that marks relatives in Bemba would then also be treated as a lexical entry with

26. Unfixed nodes are used in, for example, left-dislocated focus constructions and questions. Thus, in Who did John see? Who starts out as an unfixed node that is only later merged at the object position. 
the full specification given in (41), providing instructions for the decoration of an unfixed node. ${ }^{27}$

Lexical entry for low tone relativizer

$$
\begin{array}{lll} 
& \text { IF } & ? \operatorname{Ty}(\mathrm{e}), ? \exists \mathrm{x} \operatorname{Tn}(\mathrm{x}),\langle\uparrow *\rangle\left\langle\mathrm{L}^{-1}\right\rangle \mathrm{Fo}(\mathrm{x}) \\
& \text { THEN } & \operatorname{IF}\langle\uparrow *\rangle\left\langle\mathrm{L}^{-1}\right\rangle\left\langle\uparrow_{0}\right\rangle ? \mathrm{Ty}(\mathrm{cn}) \\
{\left[{ }^{\prime}\right]_{\text {REL }}} & & \operatorname{THEN} \operatorname{put}(\mathrm{Fo}(\mathrm{x}), \operatorname{Ty}(\mathrm{e}),[\downarrow]) \\
& & \text { ELSE Abort }
\end{array}
$$

\section{ELSE Abort}

The lexical entry, in effect, ensures the semantic relation between the head noun and the relative clause. The information from the lexical entry is parsed at the outset of the relative clause and licenses the decoration of an unfixed node with a copy of the variable of the head noun. It is important that the copy is an incomplete variable that is interpreted by being bound by the common noun of the head noun. As we have already seen, launching a LINK structure from this variable (at the Ty(e) node it decorates) forces a restrictive interpretation of the relative, rather than providing additional information to an already completed Ty(e) term.

Thus, in a perception-based grammar, conjoint tone marking provides the hearer with information that a following LINK structure must be launched from the variable node, rather than from the higher Ty(e) node, as this is what induces a restrictive interpretation. Relative low tone, on the other hand, provides instructions in its lexical specification for the decoration of an unfixed node that ensures its semantic relation with the head noun, thereby allowing a relative interpretation to obtain. In both cases, tone marking provides specific information about how the semantic representation from the words encountered has to be constructed. ${ }^{28}$

\section{Conclusion}

The restrictive versus non-restrictive interpretation of Bemba relatives has been shown to interact with conjoint tone on the head noun. The presence of conjoint tone indicates the restrictive interpretation, and its absence, the non-restrictive

27. In (41) $\uparrow$ means 'above the current node', $\downarrow$ means 'below the current node', $*$ is an as yet unknown location (i.e., an unfixed node), subscripts 0 and 1 refer to argument (left-hand daughter) and functor (right-hand daughter) nodes, respectively, and $\left\langle\mathrm{L}^{-1}\right\rangle$ refers to a LINK relation.

28. Space restrictions preclude a fuller exposition, but the aim of the foregoing is clear; in a model of grammar where syntactic representations are built on-line, information from both syntax and phonology can influence the process of tree growth. The reader is referred to Cann, Kempson and Marten (2005) for the full details of DS. 
one. This distinction interacts with the possibility of marking relatives tonally. Thus, while segmentally marked relatives can induce both restrictive and nonrestrictive interpretations, tonally marked relatives are always restrictive. In addition, the tonal strategy of relativization is unavailable in headless relatives. In an interface account of the syntax-phonology relation this can be regarded as constraints on the alignment of major phrases. A possibility that alignment constraints may be actual interface constraints making reference to syntactic boundaries such as $\mathrm{CP}$ has been investigated. Either way, phonological phrasing was shown to be the deciding factor in the choice between two competing syntactic analyses.

Finally, an alternative feeding relation between phonology and syntax was briefly explored in DS. It was shown that in a grammar where syntactic trees are built on-line, phonology, just like syntax, can drive the growth of syntactic representations, thereby revealing a tighter link between the two modules. The choice of which of these two approaches best captures empirical facts is one I leave to a future occasion.

affiliation???

\section{References}

Bianchi, Valentina (2000). The raising analysis of relative clauses: A reply to Borsley. Linguistic Inquiry 31: 123-140.

Barwise, Jon and John Perry (1983). Situations and Attitudes. Cambridge, MA: MIT Press.

Benmamoun, Elabbas (2000). Agreement asymmetries and the PF interface. In Research in Afroasiatic Grammar, Jacqueline Lecarme, Jean Lowenstamm and Ur Shlonsky (eds.), 23-40. Amsterdam: John Benjamins.

Boersma, Paul and David Weenink (2005). Praat: Doing phonetics by computer (version 4.4.02). http://www.praat.org.

Cann, Ronnie, Ruth Kempson and Lutz Marten (2005). The Dynamics of Language. Oxford: Elsevier.

Cheng, Lisa and Nancy C. Kula (2006). Syntactic and phonological phrasing in Bemba relatives. ZAS Papers in Linguistics 43: 34-51.

Chomsky, Noam (1981). Lectures in Government and Binding. Dordrecht: Foris.

- (2001). Derivation by phase. In Ken Hale: A Life in Language, M. Kenstowicz (ed.), 1-52. Cambridge, MA: MIT Press.

Demirdache, Hamida (1991). Resumptive chains in restrictive relatives, appositives, and dislocation structures. Unpublished Ph.D. dissertation, MIT, Cambridge.

Demuth Katherine and Carolyn Harford (1999). Verb raising and subject inversion in comparative Bantu. Journal of African Languages and Linguistics 20: 41-61.

Givón, Talmy (1972). Studies in chiBemba and Bantu grammar. Studies in African Linguistics. Supplement 3. Ohio State University: Department of Linguistics and Center for African Studies.

Golston, Chris (1995). Syntax outranks phonology: Evidence from Modern Greek. Phonology 12: 343-368. 


\section{$230 \quad$ Nancy C. Kula}

Grosu, Alexander and Fred Landman (1998). Strange relatives of the third kind. Natural Language Semantics 6: 125-170.

Guasti, Maria Teresa and Marina Nespor (1999). Is syntax phonology-free? In Phrasal Phonology, René Kager and Wim Zonneveld (eds.), 73-97. Nijmegen: Nijmegen University Press.

Harford, Carolyn and Katherine Demuth (1999). Prosody outranks syntax: an Optimality approach to subject inversion in Bantu relatives. Linguistic Analysis 29: 47-68.

Henderson, Brent (2006). The syntax and typology of Bantu relative clauses. Unpublished Ph.D. dissertation, University of Illinois at Urbana-Champaign.

Hornstein, Norbert, Jairo Nunes and Kleanthes K. Grohmann (2005). Understanding Minimalism. Cambridge: Cambridge University Press.

Kaier, Jieun (2005). Incremental parsing in Korean: At the syntax-phonology interface. Ms., Kings College London.

- (in prep). Incremental parsing and the architecture of grammar: At the syntax-phonology interface. Unpublished Ph.D. dissertation, Kings College London.

Kamwangamalu, Nkonko M. (1988). 'C-command' and the phonology-syntax interface in Ciluba. Studies in the Linguistic Sciences 18 (2): 87-109.

Kaye, Jonathan (1989). Phonology: A Cognitive View. Hillsdale, New Jersey: Lawrence Erlbaum Associates.

Kayne, Richard (1994). The Antisymmetry of Syntax. Cambridge, MA: MIT Press.

Kempson, Ruth, Wilfried Meyer-Viol and Dov Gabbay (2001). Dynamic Syntax. Oxford: Blackwell.

Kula, Nancy C. (2002). The Phonology of Verbal Derivation in Bemba. LOT dissertation series 65, Utrecht.

Marten, Lutz and Nancy C. Kula (in prep). Prosody and the dynamic construction of semantic representations. Ms., SOAS.

McCarthy, John and Alan Prince (1993). Generalized alignment. In Yearbook of Morphology, Geert Booij and Jan van Marle (eds.), 79-153. Dordrecht: Kluwer.

Meeussen, Achille E. (1971). Relative clauses in Bantu. Studies in African Linguistics. Supplement 2: 3-10.

Nespor, Marina and Irene Vogel (1986). Prosodic Phonology. Dordrecht: Foris.

Nsuka, Nkutsi F. (1982). Les Structures Fondamentales de Relatif dans les Langues Bantoues. Tervuren: Musee Royal de L'Afrique Centrale. Annales-Serie 8, Sciences Humaines 108.

Oger, Louis (1979). Learn Bemba the Easy Way. Illondola, Chinsali: Language Centre.

Peranteau, Paul, Judith Levi and Gloria Phares (eds.) (1972). The Chicago Which Hunt. Papers from the Relative Clause Festival. Chicago, Illinois: CLS.

Prince, Alan and Paul Smolensky (2004). Optimality theory: Constraint interaction in generative grammar. In Optimality Theory in Phonology, John McCarthy (ed.), 3-71. Oxford: Blackwell Publishing.

Sambeek, van J. (1955). A Bemba Grammar. London: Longmans, Green and Co.

Selkirk, Elisabeth (1984). Phonology and Syntax: The Relation between Sound and Structure. Cambridge: MIT Press.

- (1995). The prosodic structure of prosodic words. University of Massachusetts Occasional Papers 18: Papers in Optimality Theory: 439-469. GLSA, University of Massachusetts, Amherst.

Sharman, John Compton (1956). The tabulation of tenses in a Bantu language (Bemba: Northern Rhodesia). Africa 26: 29-46.

Sharman, John Compton and Achille E. Meeussen (1955). The representation of structural tones, with special reference to the tonal behaviour of the verb in Bemba, Northern Rhodesia. Africa 25: 293-404.

Sperber, Dan and Deirdre Wilson (1995). Relevance: Communication and Cognition. Oxford: Blackwell.

Truckenbrodt, Hubert (1999). On the relation between syntactic phrases and phonological phrases. Linguistic Inquiry 30 (2): 219-255. 
Truckenbrodt, Hubert (2005). A short report on intonation phrase boundaries in German. Linguistische Berichte 203: 273-296.

Walusimbi, Livingston (1996). Relative Clauses in Luganda. Cologne: Rüdiger Köppe Verlag.

Zwicky, Arnold M. and Gregory K. Pullum (1986). Two spurious counterexamples to the principle of phonology-free syntax. Ohio State University Working Papers in Linguistics 32: 92-99. 